\title{
Isozymes: Application for Population Genetics
}

\author{
Vibeke Simonsen
}

Additional information is available at the end of the chapter

http://dx.doi.org/10.5772/45875

\section{Introduction}

Electrophoresis as such has been applied for many purposes, among these, analysis of isozymes or isoenzymes. As the designation indicates, this is a group of enzymes having the same catalytic ability, i.e. they catalyse the same chemical reaction. Due to the fact that enzymes are proteins and built from amino acids, they possess an electric change - so isozymes are enzymes with the same catalytic ability, but different electric charge. The charge will cause the enzyme to migrate in an electric field, the migration rate may be faster or slower, depending on the carrying media (see section 3 on electrophoresis) and the power applied. In order to detect the enzyme, the substrate for the particular enzyme and needed co-factors are added, so that the enzymatic reaction can take place. An array of enzymatic detection methods based on for instance histochemical or fluorogenic procedures are known (Manchenko 1994). The revealed pattern is called a zymogram (Fig.1).

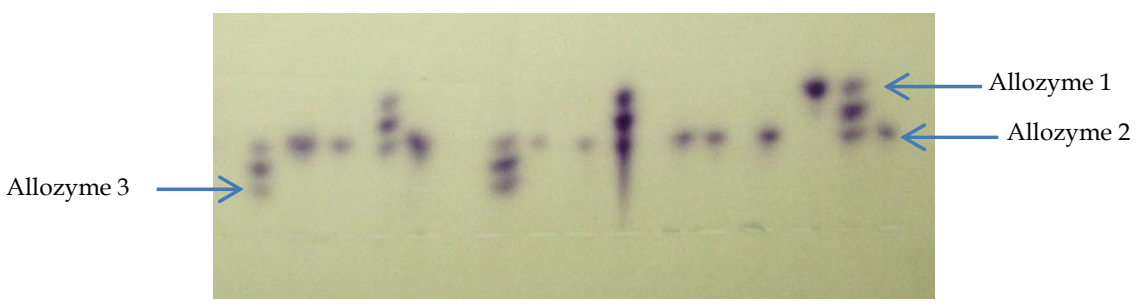

Figure 1. Zymogram of the enzyme glucosephosphateisomerase from 15 individual sprat eggs, dimeric enzyme with three allozymes. For further interpretation, see section 5

Proteins are gene products, which mean that they are an easy way to get information on genetic variation. If more zones of a particular enzyme are revealed in the same zymogram, then the enzyme consists of isozymes. If one zone is interpreted as being the product of one gene, it may reveal different alleles of the gene and, hence, this particular isozyme consists of various allozymes as shown in Fig. 1. Interpretation of the zymograms leads to estimation 
of allelic frequencies, which is the fundament of population genetics under the assumption that the genes are inherited in accordance with the Mendelian laws. Another important feature of enzymes is that they may consist of one, two, three or more polypeptides. As the enzymes perform the same reaction needed in the metabolism of the organism and that metabolism more or less is universal, the molecular structure is universal. That means that if an enzyme is a dimeric enzyme, built by two polypeptides, this structure will be found regardless of plant species, insect species or any other organism studied, see section 5.1 on interpretation.

\subsection{Procedures needed for studying isozymes}

When studying isozymes, five major procedures must be considered: Sampling and storage, preparation of the samples for electrophoresis, electrophoretic procedure, detection procedure for the isozymes, and the interpretation of the zymograms.

\section{Samples}

As mentioned above, one of the key observations in population genetics is the detection of alleles used for estimation of allelic frequencies. In order to achieve a reliable estimate of allelic frequencies, many individuals must be analysed, at least 30 in order to minimise the variance of the estimate of the allelic frequencies (see e.g. Hedrick 1983). When studying vulnerable species, for instance species with low population size, the method for sample collection has to be considered. Two methods for sample collection are considered:

None destructive method where the individual can continue life

Destructive method which will cause the death of the individual

\subsection{None destructive methods}

None destructive methods require that the samples used for detecting isozymes are removed from the individuals at site of collection. In the case of plants, the samples may consist of leaves or seeds collected from individual plants. For animals the samples may consist of a small amount of blood that can be removed without killing the animal, and with special equipment it may also be possible to remove small biopsies or hair samples. If hair is pulled out, the small tissue sample on the tip of the hair can be used for analysis of isozymes.

\subsection{Destructive methods}

As mentioned, destructive methods lead to the organism being killed. In this case, it has to be considered how to utilise the samples in an optimal way in order to reduce further collection. When dealing with plants, in the most cases the destructive method can be avoided. However, when using seeds, this will result in a reduction in the next generation, so collecting seeds is a partially destructive method. However, seedlings as samples for 
analysis of isozymes are often a good choice due to the soft material compared to the fully grown plant. Many small invertebrates have a size that only allows one analysis, e.g. collembolans, but other invertebrates, e.g. earthworms, can support several analyses however, the collecting method will be destructive. Many fish species when caught will die immediately, so removing biopsies will not save the fish. Analysing fish eggs is a destructive method which will affect the next generation. However, many fish species produce a huge number of eggs, so the actual damage may be small, depending on the vulnerability of the species.

\subsection{Transportation}

Depending on the species, the samples may either be frozen or kept in a cold box with ice when transporting the samples back to the laboratory. It is crucial that the samples are kept cold in order to avoid destruction of the proteins and, hence, the enzymes. Furthermore, refreezing the samples will also destroy the proteins, so the number of times for freezing/thawing the samples has to be minimised. Leaves or seeds can easily be transported in a cool bag with cooling blocks if the transportation can be done in one day in the temperate climate zone. If the material is frozen, transportation in a cool bag or a thick foam box with cooling blocks may be sufficient to keep the samples cold, so the activity of the enzymes is not reduced significantly. Frozen fingerlings of Indian major carps were transported this way from Bangladesh to Denmark and later analysed for isozymes with success, see Fig. 2. Transportation time was about 24 hours. For longer storage, the tissue samples have to be kept either at $-80^{\circ} \mathrm{C}$ or in liquid nitrogen. For many organisms, storage of none treated samples are better for storage than solutions of the samples, e.g. a small tissue sample in a plastic bag will do better than a solution of the tissue during storage, see preparation of samples, section 2.4 .

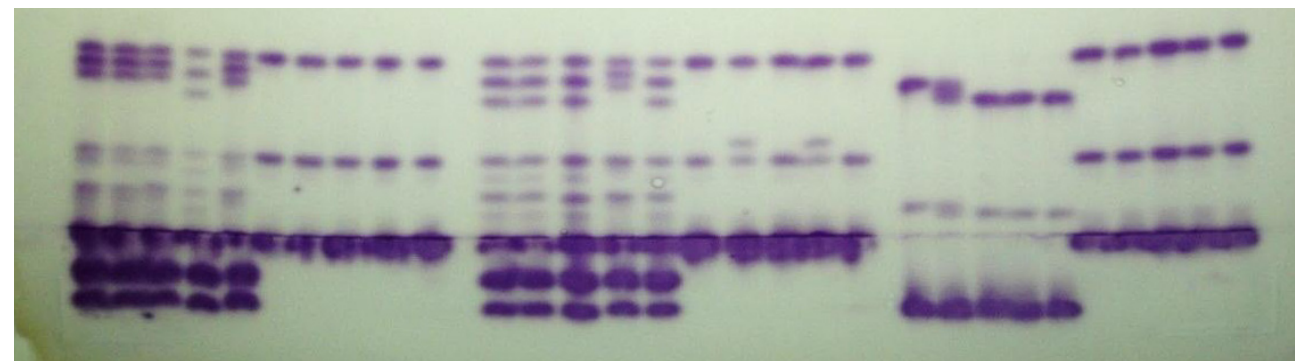

Figure 2. Zymogram of the enzyme glucosephosphateisomerase from Indian major carps, from left to right: 5 hybrids between mrigal and rohu, 5 hybrids between catla and rohu, 5 hybrids between catla and mrigal, 5 rohu, 5 mrigal and 5 catla

\subsection{Preparation of samples}

Preparation of samples for the electrophoretic procedure may be done in various ways, depending on the organism and the electrophoretic procedure chosen. The simplest way is 
to use a drilling machine with a glass or plastic rod. A small about of a buffer solution, often the gel buffer, is added and the sample with the buffer is treated with the drilling machine. When dealing with very tough samples, a small amount of sand can be added. After this procedure, the samples are centrifuged and the supernatant is used for the application procedure. It is important that the samples are kept cold during the process in order to minimise the loss of enzyme activity. More advanced milling machines are available and they give a better grinding of the material. Depending on the organism, it may be an advantage to add various chemicals to the grinding buffer, and especially for plants an array of chemicals are suggested (Soltis \& Soltis 1990). However, seedlings seem to do just as well with a buffer as grinding solution. Sonication may also be a method for squeezing the material as is treatment with liquid nitrogen.

Depending on the application method, it may be necessary to add sucrose or other chemicals that increase the density of the sample solution. This is often used when the samples are loaded on the surface of the gel, either on a small piece of filter paper (e.g. Whatman No. 3MM) or as a droplet (1-2 $\mu \mathrm{L})$. Various application templates may be used. It must be mentioned that fish eggs, which are stored in $40 \%$ sucrose (Paaver, pers. comm.), can be picked up with a forceps after the sucrose with the eggs is spread on a piece of filter paper, thereby removing the liquid. A single egg can be picked up and placed on a piece of filter paper (size $4 \mathrm{~mm} \times 6 \mathrm{~mm}$ ) soaked with $5 \mu \mathrm{L} 40 \%$ sucrose, another piece of filter paper also soaked with $40 \%$ sucrose is placed on the top, and the whole sandwich is squeezed with a spatula. One piece of paper may be used immediately and the other piece may be stored in an Eppendorf tube $(0.5 \mathrm{~mL})$ at $-80^{\circ} \mathrm{C}$ and used later for electrophoresis.

\section{Electrophoresis}

Electrophoresis is the migration of electrically charged molecules in an electric field. In order to establish an electric field which can be handled, a supporting media is needed. The media may be paper, agar or agarose, starch, cellulose acetate or polyacrylamide. Each of these media has advantages and disadvantages, so one has to select a media which suits to the organism that has to be analysed. Among the media mentioned, I have no experience with paper or cellulose acetate.

The electrophoresis may be performed either vertically or horizontally. Regardless of orientation which you are using, you must ensure that the gel is kept cold during the procedure. The electrophoretic procedure develops heat, and the heat may destroy the activity of the enzyme. In general, the set-up consists of buffer trays which carry the electrodes providing the electric field and provides contact to the carrying media and the gel. When using a horizontal set-up, the contacts may be filter paper, cloths or sponges, which establish the electric field across the gel. It must be mentioned that some enzymes are sensitive to the material from which the contact is made, but ususally filter paper, Whatman quality, will not harm the enzymes. A horizontal set-up is shown in Fig. 3. 


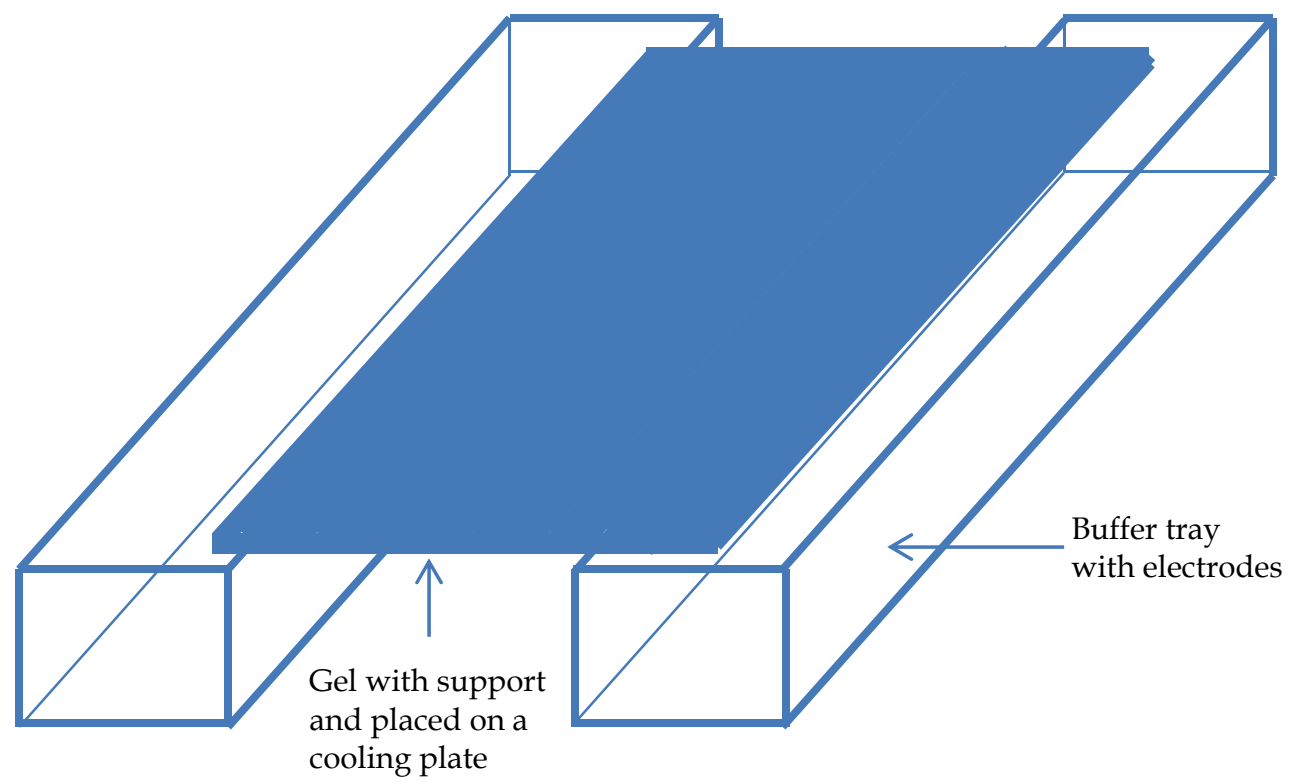

Figure 3. Drawing of horizontal set-up

\subsection{Electrophoresis performed with agar or agarose as supporting media}

The two methods described in this paragraph are horizontal set ups. Years back, certain purified agars were adequate for doing electrophoresis of e.g. haemoglobin, but nowadays various agaroses are better suited for the electrophoretic procedure. The pore size formed by the polymers is dependent on the concentration of agar/agarose. Due to the fact that there has been a high demand for high quality agarose for separating DNA fragments, many varieties of agarose have been developed, among these also products suitable for proteins.

\subsubsection{Electrophoresis performed with agar or agarose on microscope slides}

A simple set-up is to use microscope slides for support of the media. The agar/agarose solution $(1 \%)$ is cooked in water bath or in microwave oven with the buffer used for electrophoresis and the cleaned slides are coated with $2 \mathrm{~mL}$ agar/agarose solution, using a pipette. The samples are applied in a slit (one slit, one sample) made by filter paper placed vertically on the slide, see Fig. 4, or holes punched out by suction with a capillary pipette. Depending on the method used, one to four samples may be applied to one microscope slide and the electrophoresis is performed immediately after the application. An array of buffers may be used, for suggestions, see Richardson et al. (1986). 


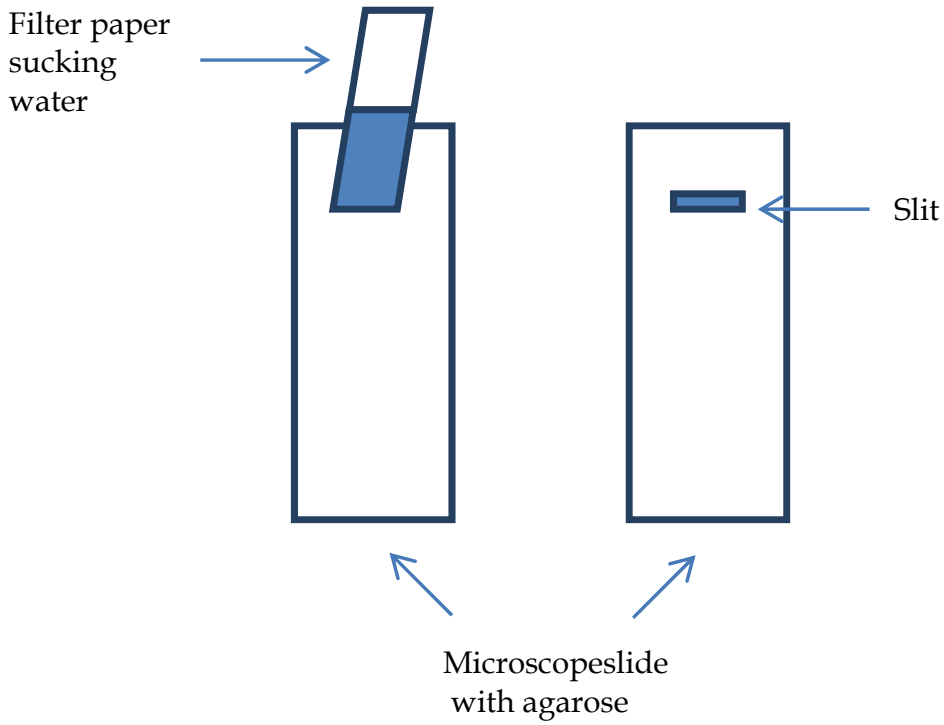

Figure 4. How to make a slit on an agar/agarose gel. The blue quadrangle at the left figure is filter paper, the blue zone shows water (buffer) migrating up in the filter paper, the blue zone on the right figure illustrates the slit

\subsubsection{Electrophoresis performed with agar or agarose on glass plates}

A different approach is to use glass plates $100 \mathrm{~mm} \times 100 \mathrm{~mm} \times 1 \mathrm{~mm}$ and Gel Bond film for agarose. The film is rolled on the glass plate with $10 \%$ glycerol as "glue". Strips of Dymo tape are placed on another glass plate, so that when the two glass plates are placed together by using Bulldog Clamps, the space between them is $0.2 \mathrm{~mm}$. Thickness of the gel can be increased by adding more Dymo tape strips. The plate with the Dymo tapes is siliconated. The sandwich with a syringe needle between the glass plates is placed in a hot cabinet $\left(70^{\circ} \mathrm{C}\right)$ for 30 minutes. When warm, the hot agar/agarose solution, cooked in the same way as mentioned in section 3.1.1, is added using a syringe (also hot) with a gentle pressure on the syringe. When the moulding form is nearly filled, the syringe with the needle is removed. The gels are left between the two glass plates and may be stored this way for a week in the refrigerator in a box with moist, but not soaking wet, paper towel.

Prior to applying the samples, the sandwich is opened and the gel on the Gel Bond is placed on a cooling plate. Gel is removed from the Gel Bond film, creating $1 \mathrm{~cm}$ rim around the gel, see Fig. 5. Application may be done either in punched holes, by a sample application strip made from plastic with slits or the sample applicator developed for the Pharmacia Phastsystem. It may be advantageous to dry the area, where the samples will be applied, with a piece of filter paper, but this operation must be done very gently. On this size of gel, 8 to 16 samples may be applied. Furthermore, as the application takes place on the top of the gel, it may be advantageous to have $10 \%$ sucrose in the sample grinding buffer. As these 
gels are thin, cooling from beneath is sufficient. However, there may be a risk of drying out of the gel, especially the $0.2 \mathrm{~mm}$ gel, however, covering the surface with a small plastic film may prevent this. The contact between the gel and the electrodes may be filter paper dipped in the buffer trays containing adequate buffer and partially covering the gel. Another possibility is to use two strips of Whatman No. 17 soaked in buffer and place the electrodes on top of these, see Fig. 5 .

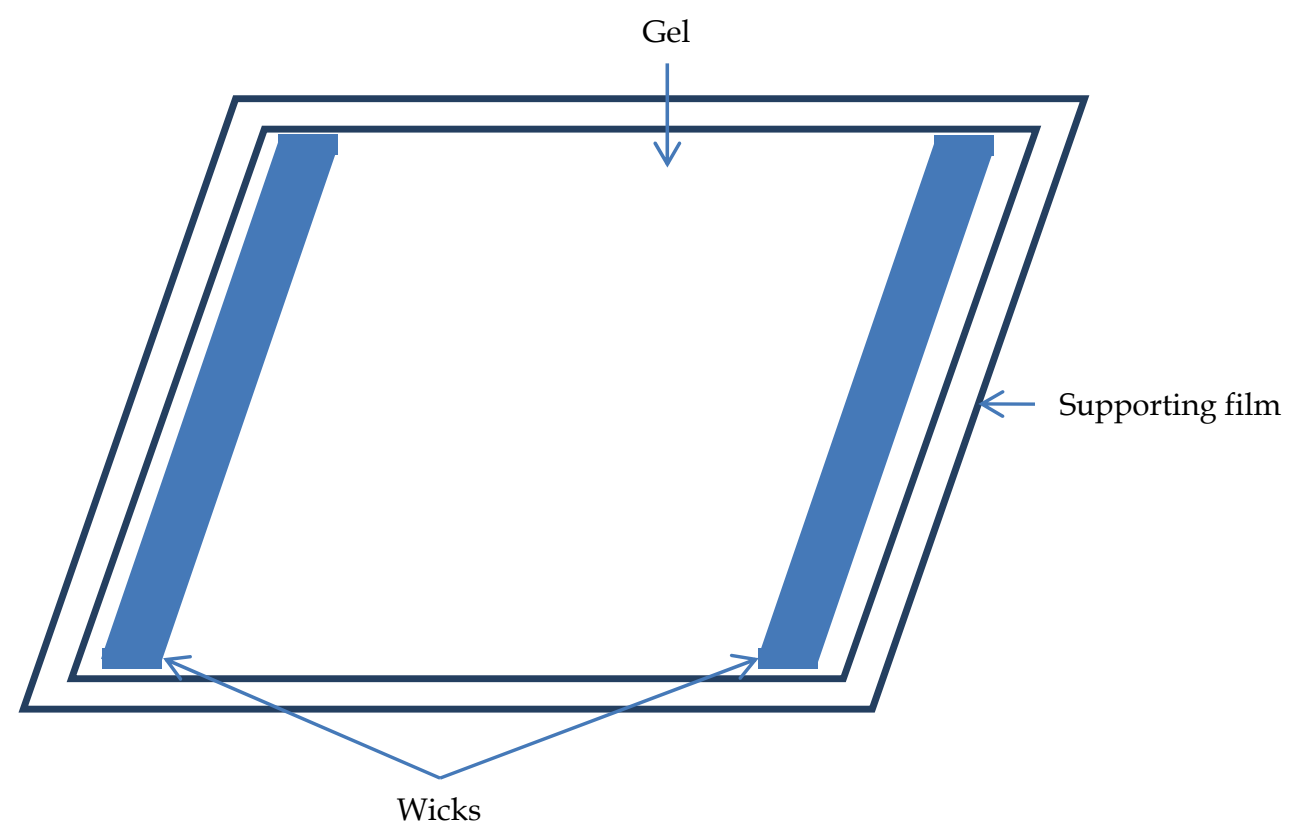

Figure 5. Set up with filter paper as buffer container

The running time depends on the enzyme studied, but as a rule a running time of about $1 / 2$ 1 hour is sufficient. Various dyes, e.g. bromphenol blue, may be applied to see how far the front is running, and the closer to the edge the better. How much voltage and current to apply depends on the buffer and the thickness of the gel. The concentration of agar/agarose will also have an impact on the electrophoretic procedure.

\subsection{Starch gel electrophoresis}

Horizontal starch gel electrophoresis is a well-described method that also provides buffers for gels and trays, see Ferguson (1980) and Murphy et al. (1996). This procedure uses potato starch hydrolysed, in other words, the starch molecules form a structure with pores. The pore size depends, more or less, on the starch gel concentration.

Various moulding forms can be made, and the ones used in our lab have been constructed by a plexiglass frame and Mylar film glued together with high vacuum grease. The size of 
the frame is $250 \mathrm{~mm} \times 190 \mathrm{~mm} \times 6 \mathrm{~mm}$ outer size, leaving a form for the gel of $210 \mathrm{~mm} \times$ $150 \mathrm{~mm} \times 6 \mathrm{~mm}$, and the width of the frame is $20 \mathrm{~mm}$. The size of the gel allows a horizontal slicing yielding three slices that can be stained individually, i. e. three enzymes can be detected in one gel. The concentration of starch used for this purpose was $12 \%$. It is possible to use thicker gels and they will allow more slices of the gel for detecting enzymes, but then the cooling has to be increased. A higher starch concentration also is possible, but the higher concentration, the slower the migration. The cooling set up is a cooling plate underneath the gel, as shown in Fig. 3, and a tray with crushed ice on the top of the gel, so you have a kind of cooling sandwich with the gel in the middle. The cooling is strongly needed, as the rather thick gel will developed a high amount of heat which will destroy the activity of the enzymes needed for detection.

The preparation of a starch gel consists of cooking the gel, evaporation of the gel and gel settling. Two thirds of the buffer used for the gel is heated to cooking point using cooking facilities as open fire, electric cooking plate or microwave oven. The starch is suspended in the rest of the buffer, the suspension is added to the hot buffer and the whole solution is swirled around for mixing. The hot solution is re-heated to boiling point two or three times, allowed to settle for a few minutes and then evaporated. It is important to avoid air in the gel solution, as it may damage the electrophoretic procedure. If evaporation is not possible, cooking the solution several times may do the job. Upon evaporation, the solution is poured into the gel frame, left for 15 minutes for settling, and then placed on the cooling plate for another 15-30 minutes. Prior to being placed on the cooling plate, the gel has to be covered with a plastic sheet to avoid loss of liquid. The gel has to be solid before applying the samples.

A slit is cut in the gel for sample application. The samples are treated as described in section 2. The supernatant of the sample is sucked up in a piece of Whatman 3MM filter paper or similar paper, size $4 \mathrm{~mm} \times 6 \mathrm{~mm}$, excess liquid is removed and the filter paper with the sample is applied in the slit.

The gel should run for three hours at $80 \mathrm{~mA}$ if possible. The contact between the electrodes in the buffer tray and the gel, see Fig. 3, is ensured with wicks made from Whatman 1 . We use 3 layers of the filter paper. Other media for contact may be used, but it has to be considered whether the medium contains substances that interfere with the activity of the enzyme.

An alternative method is to use a set up like the one shown in Fig. 5, but using wider wicks also made from Whatman 17. The wicks are sucked in the tray buffer, two thirds of the paper is placed on the gel, and the electrodes are placed on the outer edge of the filter paper. If necessary, additional tray buffer is added during the electrophoresis when the power is off.

Various dyes may be used to see how far the front has moved. After the electrophoresis, the gel is cut into three slices with a string mounted in a U-frame. Guitar string E is very well 
suited for this purpose. The adjustment of the string is done by guitar tuning pegs attached to the frame. After slicing, the gel slices are stained, see section 4.1 on staining.

\subsection{Polyacrylamide gel electrophoresis}

Polyacrylamide gels are based on polymerisation of acrylamide monomers with a linking reagent, e.g. N,N'- methylenebisacrylamide, see Westermeier et al. (2001). The pore size is controlled by the concentration of acrylamide $(\mathrm{T})$ and the cross-linker $(\mathrm{C})$, measured in per cent. The concentration is estimated as

$$
\begin{gathered}
T=\frac{(a+b) \times 100}{V} \\
C=\frac{b \times 100}{V}
\end{gathered}
$$

where $\mathrm{a}=$ acrylamide in $\mathrm{g}, \mathrm{b}=\mathrm{N}, \mathrm{N}^{\prime}$ - methylenebisacrylamide in $\mathrm{g}$ and $\mathrm{V}=$ the volume of the solution in $\mathrm{mL}$.

If $\mathrm{C}$ is kept constant and $\mathrm{T}$ is increased, the pore size decreases.

Polyacrylamide gel electrophoresis may be performed either horizontally, as the system shown in Fig. 3, or vertically. Various equipment for electrophoresis can be purchased from professional companies. As for starch gel electrophoresis, various buffers may be applied, see e.g. Westermeier et al. (2001). Again, cooling may be important, depending on the thickness of the gel and the sensibility of the enzyme.

\subsubsection{Horizontal polyacrylamide gel electrophoresis}

Many companies offer ready-made gels that may be advantageous to use, as the acrylamide is toxic when unpolymerised. However, if the financial support is limited, the gels can easily be prepared in the lab, but a casting frame is needed. The casting frame can be a glass-plate covered with Gel Bond film (not needed if the glass plate is very thin) combined with a siliconated glass plate with a U-frame. The two glass plates are clamped together with Bull Dog clamps or similar equipment. A solution with the acrylamide, cross linker and catalysts, needed for the polymerisation and dissolved in the gel buffer is filled into the form with a syringe. A set up like one shown in Fig. 3 is applied for the electrophoresis. Application of the samples can be performed as described for agarose gel electrophoresis, except that the filter paper with the sample is placed on top of the gel. To improve the migration into the gel, $10 \%$ sucrose is added to the sample grinding buffer, see section 2.4. A few $\mathrm{mA}$ are applied for 5-15 minutes, then the filter paper is removed and a higher voltage is applied. The running time depends on the thickness of the gel and the gel buffer. If adding bromphenol blue or another dye that does not harm the sample to the grinding buffer, the migration front can be followed.

Another way to apply the samples is to construct a U-frame with slot formers. These can be made by gluing Dymo tape or other forms of tape to the glass plate, as shown in Fig. 6. 


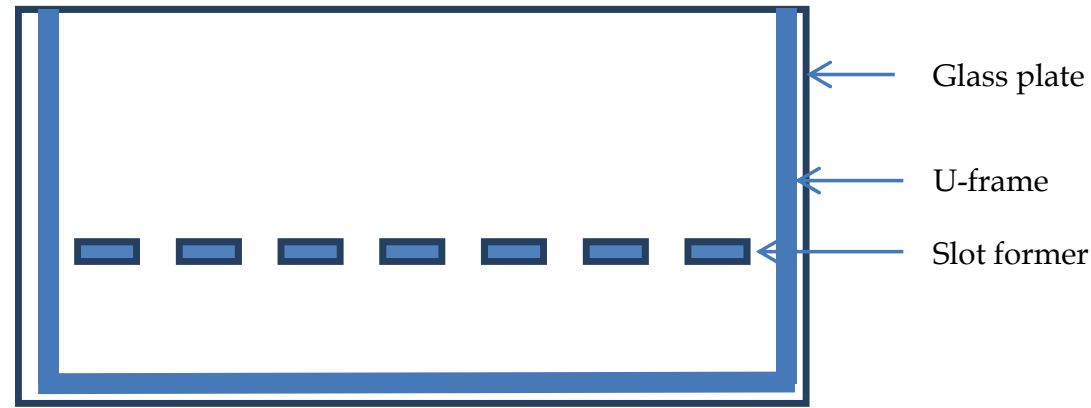

Figure 6. Template for horizontal polyacrylamide gel with slotformer

\subsubsection{Vertical polyacrylamide gel electrophoresis}

If a set-up for a vertical system is applied it may be an advantage first to make a running gel and then a stacking gel on top of the running gel. The stacking gel is helpful for organising the molecules according to size. By insertion of a comb in the stacking gel before the gel has solidified, holes for applying the samples can be made. The holes are rinsed with the tray buffer before the samples are applied. Then the holes are filled with the tray buffer and with a syringe the sample is applied in the bottom of the hole. It is a good help to have a dye in the sample supernatant, e.g. bromphenol blue, and also sucrose or another substance which makes the sample heavier than water. Again it may be advantageous to apply a few $\mathrm{mA}$ for a short while and then increase the voltage.

\subsection{Isoelectric focusing in agarose}

Isoelectric focusing can be performed either in agarose or polyacrylamide. Ampholytes are added to the gel before it solidifies. The ampholytes are chemical substances that have a high buffering capacity and low molecular weight. When power is applied to the gel, the ampholytes create a $\mathrm{pH}$ gradient across the gel, which allows proteins to be organised according to their $\mathrm{pI}$ value (isoelectric point (pI) where the protein is unchanged).

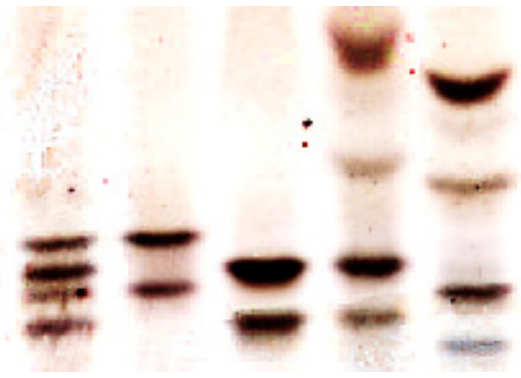

Figure 7. Zymogram of the enzyme esterase from 5 samples of plasma from minks, each allozyme consists of two bands, which means that the five individuals' four-banded phenotypes are heterozygotes. For further explanation, see Simonsen et al. (1992) 
The method using agarose as gel may be performed in a very simple way similar to the method described in section 3.1.2. An outcome of the procedure is shown in Fig. 7.

\section{Staining and data storage}

After the electrophoresis, procedures for detecting the enzymes have to be applied, i.e. the activity of the enzyme is detected. Furthermore, it is often important to be able to return to the results for further analysis, so methods for storing the gels should be considered.

\subsection{Staining}

The staining procedure is based on the activity of the enzyme. In general, many proteins are separated in a single analysis, as no attempt has been made to select specific proteins from the sample supernatant, see section 2.4, and only few proteins are visible, e. g. haemoglobin, the red dye in blood. Specific methods for detecting the proteins and, hence, the enzymes are needed.

General histochemical methods for detecting proteins as staining with e.g. Coomasie Blue are often used for visualization, but the methods are unspecific and not very sensitive. A better method is to use the antigenic ability of the protein. If an antibody to the protein exists, it is possible to detect the protein by first doing electrophoresis in the usual way. Then cut the gel into pieces that are run in the second dimension in a gel with antibody. The protein can then be revealed by special histochemical methods, for further information see Axelsen et al. (1973).

The enzymes, which have catalytic abilities, are easy to detect. When electrophoresis is done, the specific substrate for the enzyme is applied to the gel and the reaction will only take place at the spot in the gel where the enzyme is located. More spots of a specific enzyme are called isozymes, i.e. proteins with the same catalytic ability, but different electric charge. If the spots can be interpreted as the result of a locus with more alleles, then the spots are identified as allozymes.

There are three main principles for visualization of enzymes:

1. Transformation of the substrate into a visible product.

2. Transformation of the substrate into a product that can react with a dye.

3. Transformation of the substrate into a product that can be used as substrate for another enzyme. This enzyme and a dye then have to be added to the solution, depending on the reaction.

An example of the first principle is the use of 4-methyl-umbelliferyl (4-MUB)-substrates, e.g. 4-MUB-acetate. The enzyme esterase splits 4-MUB-acetate into 4-MUB and acetate, 4-MUB is fluorescent and visible by UV-light.

An example of the second principle is the use of substrates that split off naphthol. By adding diazo-compounds, the visualization takes place. 
An example on the third principle is dehydrogenases that use either NAD or NADP as coenzyme. This is depicted in Fig. 8.

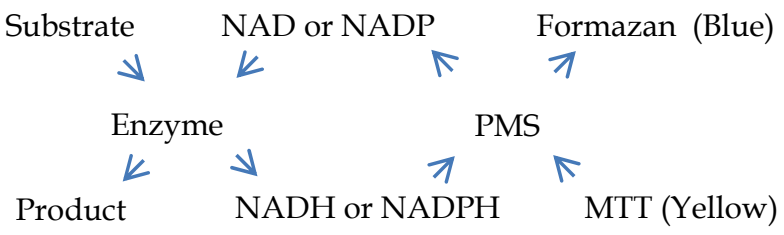

Figure 8. Visualisation of enzymes able to reduce NAD or NADP, NAD is nicotinamide dinucleotide, NADP is nicotinamide dinucleotide phosphate, NADH and NADPH are the respective reduced substances of NAD and NADP, MTT is MTT-tetrazolium salt and PMS is phenazine-methosulfate, a catalyst which transmits hydrogen ions

This method can be expanded with one step more by having an enzyme which can produce a product on which a dehydrogenase can act. A frequently used helping enzyme is glucose6-phosphate dehydrogenase. For reactions where ammonia is released, glutamate dehydrogenase works as a linking enzyme.

Many of the reactions are light sensitive, so they have to be developed in a dark cabinet and mainly a hot cabinet will do the job.

Nowadays, it is possible to visualize about 100 different enzymes. For staining procedures, see Harris and Hopkinson (1976), Tanksley and Orton (1983), Richardson et al. (1986), Pasteur et al. (1989) and Manchenko (1994).

A couple of hints regarding staining procedure are that the reactivity of the enzyme may increase with temperature and by using the optimal buffer for the specific enzyme in the staining solution. The amount of enzyme in the sample solution may be very low and especially very thin gels have a risk of rinsing off the enzyme. Applying the stain in an agar overlay on the gel may improve the result.

Prior to performing electrophoresis, it is a good idea to check the sample solutions for enzyme activity. This can be done by using the same glass plates as described in section 3.1.2. Pour $5-10 \mathrm{~mL}$ staining solution in $2 \%$ agar on a glass plate, apply a droplet of the sample supernatant on the agar surface, place the glass plate in a hot cabinet for a while and if the dye is developing there a good chance that electrophoresis of that particular enzyme will work.

\subsection{Gel storing}

There are two methods for storing the gels; either a) dry the gels and save them or b) take a photo.

All gels can be stored, but many of the stains are sensitive to light, so the stain may fade away over time. The thin agarose gels are easy to dry. For the esterases shown in Fig. 7, once stained for enzymes, the thin agarose gel is treated with $5 \%$ acetic acid for 10 minutes and 
dried at room temperature. However, the $2 \mathrm{~mm}$ thick slides of starch gel are harder to dry. Various methods have been tested and a drying oven has been developed. An easy way is to dry the agar overlayer if the stain is applied in that way. A photo is even better, as it does not take up that much storing space. This was a tedious job 20 years ago, when you had to find the right film, develop it and to do the copying in the dark room. However, nowadays it is much easier to take a photo. The best way to do this is to have light box providing transmitted light and a stand for the camera. By using various softwares for photo editing, you can enhance the bands on the gel, see Fig. 1 and 2. From the photo, it may possible to estimate the relative amount of activity if you have a multi-banded zymogram by using e.g. the software Image J (http://rsbweb.nih.gov/ij/).

\section{Data analysis}

To a wide extent, electrophoresis, applied to proteins, has been used concerning genetic investigations from the sixties and to nineties. Several books and book chapters have been written about this topic, e.g. Ferguson (1980), Richardson et al. (1986), Pasteur et al. (1989), Whitmore (1990) and Murphy et al. (1990). However, now that the PCR-technique has been developed, DNA is much more suited for genetic investigations. By analysing DNA, the genes are studied directly and not after the translation of the genetic information into proteins.

Electrophoresis is a major part of the analytic methods used for both proteins and nucleic acids, the interpretation and data analysis revealed for protein electrophoresis can be applied for analysing the results achieved by studying nucleic acids and, hence, genes. A lot of software for data analysis is available on the internet (e.g. GeneAlex written by Peakall \& Smouse (2006)). However, prior to carrying out advanced analysis of the data, it should checked up, whether the genetic marker is inherited according to the Mendelian laws. When dealing with proteins, it must also be considered whether the protein is codominant, i.e. whether the heterozygote can be recognised. Most studied individuals are diploids, i.e. have chromosomes in pairs, which means that an individual has two products (proteins) of each gene, two alleles. If the two products are identical in construction, then the individual is homozygous, but if the products are different, then the individual is a heterozygote. This scoring of phenotypes interpreted as genotypes is the fundament for applying protein electrophoresis for genetics.

\subsection{Interpretation of zymograms}

The outcome of a protein electrophoresis is called a zymogram, as mentioned in section 1. In Fig. 1, the position of three different gene products is indicated as allozyme 1, allozyme 2 and allozyme 3. Fig. 9 depicts three zymograms with allozymes designated 1 and 2.

The first zymogram in Fig. 9 is determined by a locus with two codominant alleles and the resulting protein is monomeric, which means that only one protein chain makes up the active protein. The second zymogram is the result of a locus with two codominant alleles, but the active protein is a dimer, i.e. two protein chains are needed for constructing the 
active protein. The third zymogram is the outcome of a locus with two codominant alleles, where four protein chains are needed for making the active protein.

\begin{tabular}{|c|c|c|c|c|}
\hline Monomeric & & & & $\begin{array}{l}\text { Allozyme } 1 \\
\text { Allozyme } 2\end{array}$ \\
\hline \multirow[t]{2}{*}{ Dimeric } & & & & Allozyme 1 \\
\hline & & & & Allozyme 2 \\
\hline \multirow[t]{2}{*}{ Tetrameric } & & & & Allozyme 1 \\
\hline & & & & Allozyme 2 \\
\hline Phenotype & 1 & 12 & 2 & \\
\hline Genotype & $1 / 1$ & $1 / 2$ & $2 / 2$ & \\
\hline
\end{tabular}

Figure 9. Depiction of three different proteins with monomeric, dimeric and tetrameric structure, each protein has two allozymes 1 and 2. Phenotype indicates the phenotypic interpretation of the zymogram and genotype the genetic interpretation.

As shown in Fig. 9, the genotypic interpretation is determined from the phenotypic interpretation. In theory, it is expected that the two bands seen for the genotype $1 / 2$ are of equal strength for a monomeric enzyme, but that is not always the case. If the two allozymes for the dimeric enzyme combine randomly, the three banded phenotypes seen for the heterozygous individual should come out as 1:2:1. The representing allozyme 1 consists of two units of allozyme 1, the band in the middle consists of one unit of allozyme 1 and one unit of allozyme 2, and the band representing allozyme 2 consists of two units of allozyme 2 . In a similar way, the five bands for the tetrameric enzyme should come out in the ratio 1:4:6:4:1, when the two units combine randomly.

Some times more zones are revealed in the zymogram. An example of this is shown in Fig. 2, where two zones are seen - one in the upper end of the gel and one in the lower end of the gel. Furthermore, there is a zone in the middle. The active protein is dimeric and the interpretation is that the enzyme is determined by two loci, one with three codominant alleles, located in the upper zone, and one with two codominant alleles, respectively. Fig. 10 depicts a more simple case for a dimeric enzyme determined by two loci with one and two codominant alleles. 
Zone 1

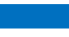

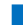

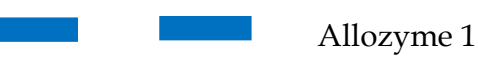

Allozyme 1

\begin{tabular}{|c|c|c|c|c|c|}
\hline \multicolumn{2}{|c|}{$\begin{array}{l}\text { Hybrid } \\
\text { zone }\end{array}$} & & & & \\
\hline \multicolumn{3}{|c|}{ Zone 2} & & & Allozyme 1 \\
\hline \multirow[t]{2}{*}{ Phenotype } & Zone 1 & 1 & 1 & 1 & \\
\hline & Zone 2 & 1 & 12 & 2 & \\
\hline \multirow[t]{2}{*}{ Genotype } & Locus 1 & $1 / 1$ & $1 / 1$ & $1 / 1$ & \\
\hline & Locus 2 & $1 / 1$ & $1 / 2$ & $2 / 2$ & \\
\hline
\end{tabular}

Figure 10. Zymogram of a dimeric enzyme determined by two loci with one and two codominant alleles, respectively. The hybrid zone consists of one unit from zone 1 and one from zone 2

Normally the fastest anodic migrating zone is determined by locus 1, the next by locus 2 and so on. The most common allele is designated 100 and the others are named according to the migration distance, e.g. for allele $75,75 \%$ of the distance from application to the location of allele 100, see Fig. 11. However, the nomenclature of the alleles is not very rigid. The only feature is that a reference is needed, so the nomenclature is consistent all the way through the study.

Allozyme 1

Allozyme 2

Allozyme 3

Allozyme 4

Application

Phenotype

100

125

50

75

Genotype

$100 / 100$

$125 / 125$

$50 / 50$

$75 / 75$

Figure 11. Designation of alleles for a monomeric enzyme 
In general, an enzyme is written with capitals, the enzyme esterase as EST. If you speak about the locus, the designation is EST and if you speak about an allele, the name is written as EST-1-100 or EST-1 ${ }^{100}$, this means esterase locus No. 1 and allele 100. However, there is no strict rule about how to do this. The abbreviations of the enzymes may be found in many books on enzyme electrophoresis.

\subsection{Expression}

Due to the fact that enzymes are produced within an individual, the physiology of the individual as well as the environment may have an impact on expression of the enzyme. All cells have the same chromosomal set with the exception of semen and eggs, so in theory all enzymes could be expressed in all cells. However, due to cell differentiation not all enzymes are important for all cells, so a regulation of the expression in the various tissues is found. An example is shown in Fig. 12.

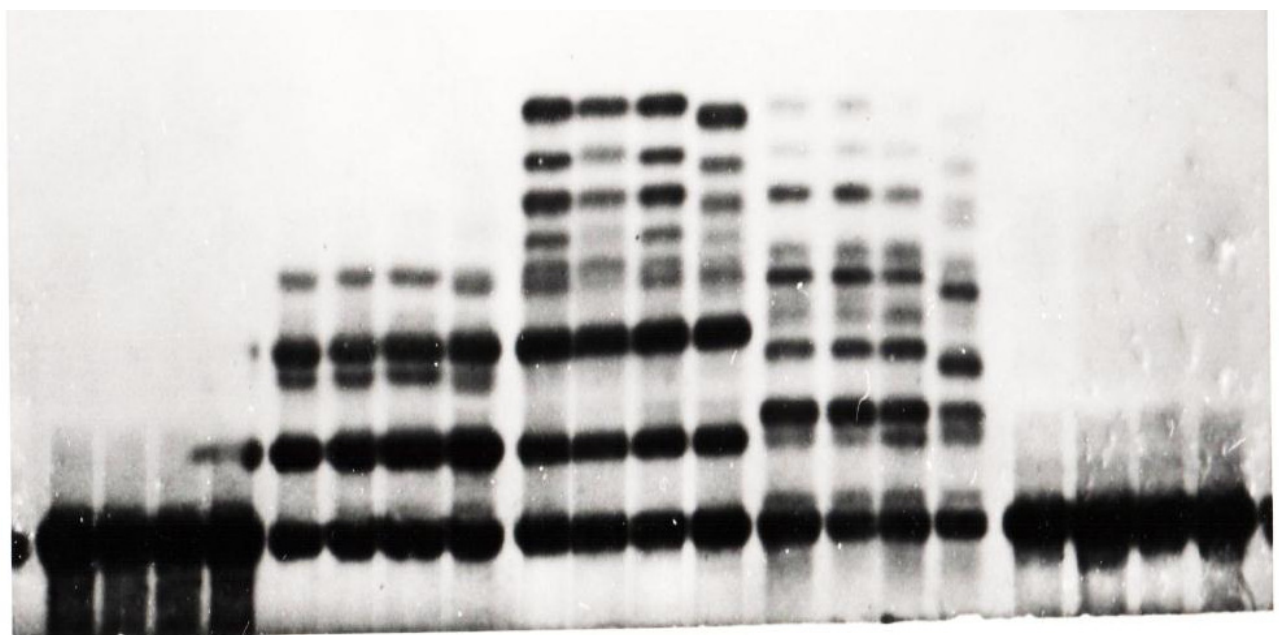

Figure 12. Zymogram of lactate dehydrogenase from four eelpouts. From left to right, 4 samples of heart tissue, 4 brains, 4 eyes without vitreous body, 4 vitreous bodies and 4 muscles. For further information, see Simonsen \& Christiansen (1985)

The lactate dehydrogenase is a tetrameric enzyme determined by three loci in the eelpouts, where only one locus is expressed in all tissues investigated. The interpretation of the zymogram is difficult and is only possible when finding rare variants of the three loci (Simonsen \& Christiansen 1985). 
Another feature may be age, and a good example of this is haemoglobin, as described by Harris (1980). As the expression may vary due to tissue and age, it is very important to collect the samples from individuals of similar age and use the same tissue throughout an investigation.

Sometimes null alleles or silent alleles are observed. To be sure that it is a true silent allele and not just a poor sample, it is important that at least two zones are seen for the enzyme. If one zone is present and the other zone is absent in a particular individual, the conclusion regarding the presence of a silent allele is reliable. Remember that the electrophoretic procedure is a tough treatment of the proteins, and even if the allozyme is not working when developed, it may function in the individual.

Expression of an enzyme may be controlled by other genes, see e.g. Poulsen et al. (1983).

\subsection{Modification}

Modification of the gene product can be done in several ways. Regarding the protein structure and folding, various small molecules may have an impact on the charge of the protein. These molecules may be a part of the protein, but may not be necessary for the enzymatic function. This may result in a copy of the original product, and an example is depicted in Fig. 13.

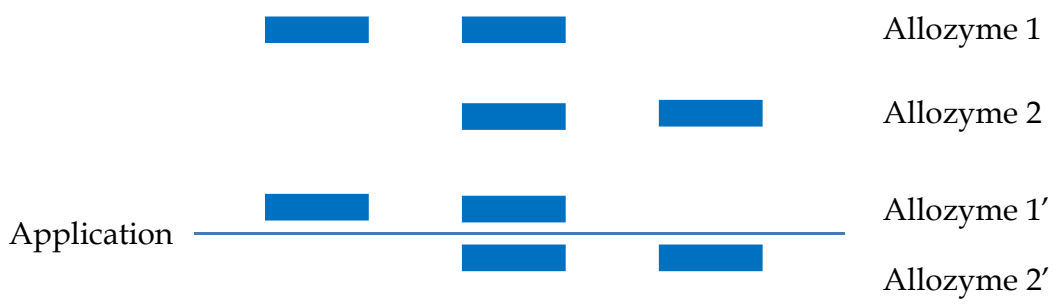

Figure 13. Depicted zymogram of adenosine deaminase from the vitreuos body of eelpouts. Allozyme 1 and 2 are seen in many tissues, but allozymes 1' and 2' are only seen in the vitreous body, see Simonsen \& Christiansen (1981)

The small molecules in the buffer may also have an impact on the zymogram, see Fig.14.

For the slice to the left and the one in the middle, each allozyme consists of two bands, whereas the last buffer only resolves one band for each allozyme.

Among many others, these examples merely illustrate how important it is to find the right tissue and electrophoretic procedure for the individuals studied. 


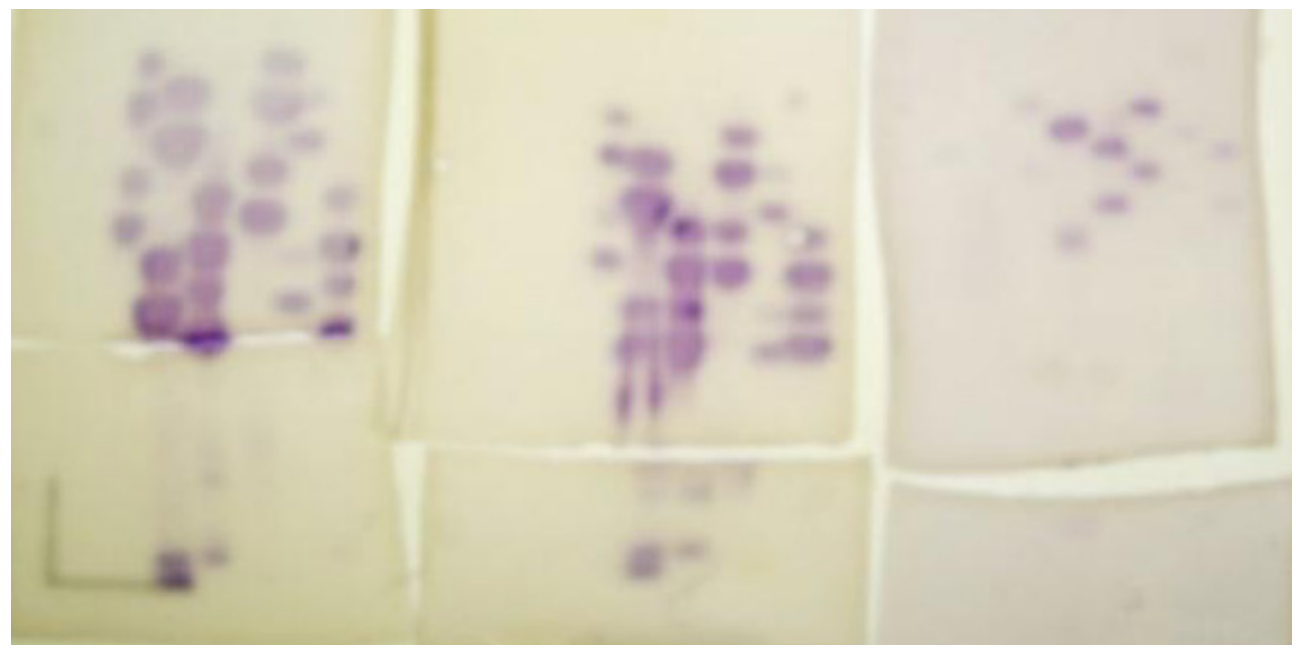

Figure 14. The enzyme phosphoglucomutase from six individuals of earthworms, analysed by using three different buffers for electrophoresis

\section{Conclusion}

In present times, analysis of proteins by electrophoresis is considered an old fashioned method despite the fact that it was a great improvement for studying genetic variation in populations fifty to sixty years ago. However, nowadays, the method is overruled by the DNA analytic methods. Despite this fact, the study of proteins together with the development of analytical software initiated an enormous step forward for our knowledge of population genetics and much of the software can be used for analysing the results from DNA methods.

Keep in mind that protein electrophoresis only reveals about $30 \%$ of all the genetic variation. Also keep in mind that the method is only sufficient for showing dissimilarities. When you have two allozymes with same migration distance on a gel, it cannot be concluded that they have identical amino acid composition, but at least they have the same electric charge. Finally, remember that the result of your study is not any better than the primary data, i.e. the zymogram.

\section{Author details}

Vibeke Simonsen

Aarhus University, Institute of Bioscience, Denmark 


\section{Acknowledgement}

I would like to thank Aarhus University for giving me 43 years of working with allozymes. Many of the examples used in the chapter have been done in co-operation with many colleagues. It has been exiting to follow the development of the electrophoretic procedures for protein studies. Furthermore, I wish to thank Charlotte Kler for the great help with the language.

\section{References}

Axelsen, N.H., Krøll, J. \& Weeke, B. (1973) A manual of quantitative immunoelectrophoresis: Methods and applications. Universitetsforlaget, Oslo, 169 p.

Ferguson, A. (1980) Biochemical systematics and evolution. Blackie \& Son, Glasgow, 194 p.

Harris, H. (1980) The principles of human biochemical genetics. Elsevier/North-Holland, Amsterdam, $554 \mathrm{p}$.

Harris, H. \& Hopkinson, D.A. (1976) Handbook of enzyme electrophoresis in human genetics. - North-Holland, Amsterdam. Pages are numbered for each section.

Hedrick, P.W. (1983) Genetics of populations. Science Books International, Boston, 629 p.

Manchenko, G.P. (1994) Handbook of detection of enzymes on electrophoretic gels. CRC Press, Boca Raton, 341 p.

Murphy, R.W., Sites Jr., J.W., Buth, D.G. \& Haufler, C.H. (1996). Proteins: Isozyme electrophoresis. In D.M Hillis, C. Moritz \& B.K. Mable (Eds.), Molecular systematics. Sinauer Associates, Inc., Sunderland, Massachusetts, pp. 51-120

Pasteur, N., Pasteur, G., Bonhomme, F., Catalan, J. \& Britton-Davidian, J. (1989). Practical isozyme genetics. - Translated by M. Cobb, Ellis Horwood Limited, Chichester, 216 p.

Peakall, R. \& Smouse, P.E. (2006) GENALEX 6: Genetic analysis in Excel. Population genetic software for teaching and research. Molecular Ecology Notes 6, 288-295.

Poulsen, H.D., Simonsen, V. \& Wellendorf, H. (1983) The inheritance of six isoenzymes of Norway spruce (Picea abies (L.) Karst). Forest Tree Improvement 16, 12-33.

Richardson, B.J., Baverstock, P.R. \& Adams, M. (1986) Allozyme electrophoresis: A handbook for animal systematics and population studies. Academic Press, London, $410 \mathrm{p}$.

Simonsen, V. \& Christiansen, F.B. (1981) Genetics of Zoarces populations. XI. Inheritance of electrophoretic variants of the enzyme adenosine deaminase. Hereditas 95, 289-294.

Simonsen, V. \& Christiansen, F.B. (1985) Genetics of Zoarces populations. XIV. Variation of the lactate dehydrogenase isoenzymes. Hereditas 103, 177-185.

Simonsen, V. (1992) Genetic polymorphism of esterase in plasma of American mink (Mustela vison L.). Animal Genetics 23, 553-555.

Soltis, D.E. \& Soltis, P.E. (1990) Isozymes in plant biology, Springer, New York, 268 p.

Tanksley, S.D. \& Orton, T.J. (1983). Isozymes in plant genetics and breeding. Part A Elsevier, Amsterdam, 516 p.

Westermeier, R., Gronau, S., Beckett, P., Berkelman, T., Bülles, J., Schickle, H. \& Thesseling, G. (2001) Electrophoresis in practice. A guide to methods and applications of DNA and protein separations, 3rd edition, Wiley-VCH, Weinheim, $349 \mathrm{p}$. 
Whitmore, D.H. (1990). Electrophoretic and isoelectric focusing techniques in fisheries management. - CRC Press, Boca Raton, 360 p. 